\title{
Porcine Pulmonary Artery and Bronchial Responses to Endothelin-1 and Norepinephrine on Recovery from Hypoxic Pulmonary Hypertension
}

\author{
MARGRID B. SCHINDLER, ALISON A. HISLOP, AND SHEILA G. HAWORTH \\ Paediatric Intensive Care Unit [M.B.S.], Bristol Royal Hospital for Children, BS2 8BJ United Kingdom; Vascular Biology and \\ Pharmacology Unit [A.A.H., S.G.H.], Institute of Child Health, London, WC1N 1EH United Kingdom
}

\begin{abstract}
Many infants recovering from acute lung disease and pulmonary hypertension still have evidence of reactive airways disease at one year of age, suggesting longer-term airway effects. We hypothesized that parallel changes in smooth muscle would occur in airways and pulmonary arteries from animals with pulmonary hypertension and during normoxic recovery. Thus, two-hour-old piglets were subjected to $3 \mathrm{~d}$ chronic hypobaric hypoxia and 3-d-old piglets were subjected to $11 \mathrm{~d}$ hypoxia. Some animals were allowed to recover in room air for 3 or $6 \mathrm{~d}$. The amount of smooth muscle and responses of isolated paired bronchial and pulmonary artery rings to endothelin-1 (ET-1) and norepinephrine were studied at the end of hypoxic exposure, on recovery and in age-matched control animals. In all hypoxia induced pulmonary hypertensive animals, smooth muscle area and ET-1 contractile response was increased in the pulmonary arteries and bronchi. Norepinephrine-induced relaxant response was impaired significantly in both bronchi and pulmonary arteries. After 3 d recovery, pulmonary arterial smooth muscle area decreased by $65 \%$, and ET-1-induced contractile responses were normal for age. In the airways, ET-1 contractile response only normalized after six days and bronchial smooth muscle was still increased. After 6 d recovery pulmonary arterial norepinephrineinduced relaxant response had returned to normal, but bronchial response remained impaired. Thus during pulmonary hypertension, both bronchial and pulmonary arterial smooth muscle area and contractile responses are increased. On recovery, regression of bronchial structural and functional abnormalities is slower than in pulmonary arteries. (Pediatr Res 60: 71-76, 2006)
\end{abstract}

A natomically, the pulmonary arteries and airways lie in close proximity and local mediator release may affect both bronchial and pulmonary vascular reactivity. Pulmonary hypertension in children with congenital heart disease is associated not only with an elevated pulmonary arterial vascular resistance and medial smooth muscle hypertrophy, but also with increased respiratory system resistance and bronchial smooth muscle hypertrophy (1).

Fifty percent of infants requiring Extra Corporeal Membrane Oxygenation (ECMO) for persistent pulmonary hypertension of the newborn still required pulmonary medications

Received October 6, 2005; accepted February 9, 2006.

Correspondence: Margrid Schindler, Ph.D., Paediatric Intensive Care Unit, Bristol Royal Hospital for Children, Upper Maudlin Street, Bristol BS2 8BJ, United Kingdom; e-mail: Margrid.Schindler@ubht.swest.nhs.uk

This work was supported by British Heart Foundation.

DOI: 10.1203/01.pdr.0000219577.01928.78 after six months, despite ECMO utilizing a strategy of lung rest to prevent lung injury (2). Twenty-six percent of infants who participated in the UK randomized ECMO trial, many of whom had severe persistent pulmonary hypertension, still had evidence of reactive airways disease with cough and wheeze at one year of age, and $8 \%$ still required regular pulmonary medications (3). These changes could be due to the damaging effects of high pressure and the high $\mathrm{FiO}_{2}$ used during the mechanical ventilation given before instituting ECMO (4), however pulmonary hypertension may have contributed to the end result by affecting both the pulmonary arteries and bronchi. The clinical findings also suggest that any bronchial changes, once present, are slow to resolve $(2,3)$. Pulmonary hypertension can also have long-term pulmonary arterial sequelae. Human adults who had had perinatal pulmonary hypertension, showed a significantly greater mean increase in pulmonary artery pressure at high altitude than was seen in controls adults with no previous history of pulmonary hypertension (5). We hypothesize that there may be parallel changes in the pulmonary arteries and bronchi during pulmonary hypertension and on recovery. We have previously found that bombesin-immunostained pulmonary neuroendocrine cells, which also contain Endothelin-1 (ET-1) and norepinephrine, are increased during pulmonary hypertension in both the pulmonary arteries and bronchi in children with congenital heart disease (1). In man, ET-1 blood levels are elevated during pulmonary hypertension, and decrease following resolution in both persistent pulmonary hypertension of the newborn (6) and pulmonary hypertension due to congenital heart disease (7). Children with elevated pulmonary vascular resistance due to congenital heart disease or primary pulmonary hypertension also have elevated plasma norepinephrine levels (8). Thus evidence is accumulating that increased ET-1 and norepinepheine activity may contribute to the pathogenesis of pulmonary hypertension in children.

We therefore exposed newborn and 3-d-old piglets to chronic hypobaric hypoxia for three or $11 \mathrm{~d}$ to produce a

Abbreviations: ET-1, endothelin-1; ET-B, endothelin-B receptor; ECMO, extracorporeal membrane oxygenation 
raised pulmonary arterial pressure and then allowed some animals to recover in room air. The change in the amount of smooth muscle and the responses of isolated paired bronchial and pulmonary artery rings to ET-1 and norepinephrine were studied at the end of hypoxic exposure and after recovery to see if there are parallel changes in pulmonary arteries and bronchi.

\section{METHODS}

To study the effect of pulmonary hypertension immediately after birth, newborn piglets (two hours old) were placed in a hypobaric chamber $\left(50.8 \mathrm{kPa}, \mathrm{FiO}_{2} 0.096\right)$ and cared for in a hypoxic environment for three days (0-3 d hypoxia group) as previously described (9). A second group of normal three-day-old piglets were placed in the hypobaric chamber for eleven days (3-14 d hypoxia group) to examine the effect of onset of pulmonary hypertension after a period of post natal adaptation. Three and 14-d-old normoxic littermates were used as controls. Some piglets from both of the hypoxic pulmonary hypertension groups were allowed to recover in room air for $3 \mathrm{~d}$. Six- or 17-d-old normoxic littermates were used as controls for these animals. Other piglets from the 3-14 d hypoxic pulmonary hypertension group were given a 6 d recovery period and 20-d-old littermates were used as controls (Table 1). The pigs received humane care in compliance with the "Guide for the Care and use of Laboratory Animals" published by the National Institutes of Health (Publication No. 80-23, Revised 1996). The study was approved by the Animal Ethics Committee of the Institute of Child Health.

The animals were killed with an overdose of pentobarbital sodium and the heart and lungs removed. The right ventricle (RV) was dissected free from the left ventricle plus septum $(L V+S)$, weighed and the $L V+S / R V$ ratio calculated.

To assess changes in the amount of bronchial and pulmonary arterial smooth muscle, lung tissue blocks were processed, cut and stained with smooth muscle alpha actin. Images of bronchi and accompanying pulmonary arteries $(0.3-2 \mathrm{~mm}$ internal diameter) were captured with a Zeiss camera and then analyzed using OpenLab (10). Bronchial and pulmonary arterial smooth muscle area, lumen perimeter and diameter were measured. To standardize the smooth muscle mass for airway and vessel size, the smooth muscle area was divided by the measured lumen circumference. Four to nine pairs of bronchi and pulmonary arteries were measured in each animal. Only those airways and arteries cut in near-perfect cross-section were included for analysis (1).

To assess if there are parallel changes in bronchial and pulmonary arterial ET-1 and adreno-receptor pharmacological responses, intra-lobar pulmonary arteries (1-2 mm diameter) and adjacent bronchi (2-3 mm diameter) were dissected free and cut into rings $2-3 \mathrm{~mm}$ long. The rings were suspended in a $10 \mathrm{~mL}$ organ chamber and isometric tension was measured with a Grass FT 0.03 force transducer (Grass Instruments, Quincy, MA) and MacLab (AD Instruments Ltd., UK) as previously described (9). The organ chambers were filled with modified Krebs-Ringer solution, bubbled with $95 \% \mathrm{O}_{2}-5 \% \mathrm{CO}_{2}$

Table 1. Number of animals, weight, sex and heart weight ratio

\begin{tabular}{|c|c|c|c|c|}
\hline & $n$ & Wt Kg & male/female & $\mathrm{LV}+\mathrm{S} / \mathrm{RV}$ \\
\hline $0-3$ days hypoxia & 9 & $1.3 \pm 0.1$ & $1: 1.2$ & $1.52 \pm 0.1^{*}$ \\
\hline 3-d-old control & 9 & $1.6 \pm 0.1$ & $1.2: 1$ & $2.01 \pm 0.1$ \\
\hline $0-3$ hypoxia $+3 \mathrm{~d}$ recovery & 8 & $1.6 \pm 0.2$ & $1: 1$ & $1.96 \pm 0.1 \dagger+$ \\
\hline 6-d-old control & 7 & $2.2 \pm 0.3$ & $1.3: 1$ & $2.58 \pm 0.2$ \\
\hline 3-14 days hypoxia & 7 & $3.0 \pm 0.2$ & $1: 1.3$ & $1.8 \pm 0.1^{*}$ \\
\hline 14-d-old control & 7 & $4.1 \pm 0.4$ & $1: 1.3$ & $3.1 \pm 0.1$ \\
\hline $3-14$ hypoxia $+3 d$ recovery & 6 & $3.26 \pm$ & $1: 1$ & $0.1 \%$ \\
\hline 17-d-old control & 6 & $3.9 \pm 0.4$ & $1: 1$ & $3.1 \pm 0.1$ \\
\hline $3-14$ hypoxia $+6 d$ recovery & 3 & $3.5 \pm 0.1$ & $1: 2$ & $2.3 \pm 0.1 \dagger+$ \\
\hline 20-d-old control & 3 & $4.9 \pm 1$ & $1.5: 1$ & $3.2 \pm 0.2$ \\
\hline
\end{tabular}

$\mathrm{LV}+\mathrm{S} / \mathrm{RV}$, left ventricle + septal weight, divided by right ventricular weight.

$* p<0.01$ when hypoxic pulmonary hypertensive animals compared to age-matched controls; $\dagger p<0.01$ when recovery animals compared to hypoxia group; $\ddagger p<0.01$ when recovery animals compared to age-matched control animals, indicating that despite some recovery, there is still significant residual RV hypertrophy in the recovery animals.

$n$, number of animals.

Values are mean + SEM. at $37^{\circ} \mathrm{C}$. The rings were stretched to their optimum resting tension and contracted with potassium chloride $(\mathrm{KCl}) 40 \mathrm{mM}$ to assess their viability.

A cumulative contractile dose-response cuve to ET-1 $\left(10^{-10}-10^{-7.5} \mathrm{M}\right)$ was performed in the arteries and bronchi from baseline resting tension. A cumulative relaxant dose-response cuve to ET-1 $\left(10^{-10}-10^{-8} \mathrm{M}\right)$ and norepinephrine $\left(10^{-8}-10^{-4} \mathrm{M}\right)$ was also performed in both pulmonary arteries and bronchi after the baseline tone had been elevated with U46619 (arteries) or carbachol (airways) to approximately $50 \%$ of the $\mathrm{KCl} 40 \mathrm{mM}$ contraction. Some rings were pre-incubated with either the Endothelin-B receptor (ET-B) antagonist BQ788 $10^{-6} \mathrm{M}$ or L-NAME $10^{-4} \mathrm{M}$ before the ET-1 relaxation.

The contractile response was expressed as developed tension (in grams $/ \mathrm{mg}$ tissue), and the relaxation response was expressed as the percentage relaxation of the pre-constricted tension induced by U46619 or carbachol. The effect of hypoxic pulmonary hypertension and normoxic recovery on ET-1 and norepinephrine-induced responses of the arteries and bronchi were determined using a general linear model with repeated measures. The heart weight ratio, animal weight and smooth muscle area were analyzed using the $t$-test with Bonferroni correction, comparing the pulmonary hypertensive and recovery animals to the age-matched normoxic controls.

\section{RESULTS}

The weight of the pulmonary hypertensive and recovery animals was not significantly different from that of agematched controls (Table 1). The male-to-female ratio was similar in the pulmonary hypertensive, recovery and control groups.

The heart weight ratio of the 0-3 d hypoxia and 3-14 d hypoxia animals indicated significant right ventricular hypertrophy compared with three and 14-d-old controls and therefore the presence of pulmonary hypertension (Table 1). Following $0-3 \mathrm{~d}$ hypoxia and $3 \mathrm{~d}$ recovery, the mean heart weight ratio was greater than in hypertensive animals $(p<0.01)$, but the ratio remained significantly lower than in $6 \mathrm{~d}$ control animals $(p<0.01)$, indicating residual right ventricular hypertrophy (Table 1). Following 3-14 d hypoxia, the heart weight ratio became greater than that of the hypertensive animals after $6 \mathrm{~d}$ of recovery $(p=0.02)$; however, it remained significantly lower than in the 20-d-old controls $(p=0.03)$, again indicating residual right ventricular hypertrophy.

The pulmonary arterial and bronchial smooth muscle area related to lumen perimeter was increased two-fold in both groups of hypoxia-exposed animals, $p<0.001$ (Table 2). When regression analysis was performed on the data from all the paired bronchi and pulmonary arteries of $0-3 \mathrm{~d}$ hypoxic pulmonary hypertensive and $3 \mathrm{~d}$ control animals, there was a significant correlation between smooth muscle area in the bronchi and pulmonary arteries $(\mathrm{r}=0.75, p<0.0001$, Fig. 1$)$. A similar correlation was found in the 3-14 d hypoxia group $(\mathrm{r}=0.86, p=0.0001)$.

In animals exposed to $0-3 \mathrm{~d}$ hypoxia there had been a significant reduction in the pulmonary arterial smooth muscle after $3 \mathrm{~d}$ recovery $(p=0.03)$, but was still greater than in age-matched controls $(p=0.001)$ being similar to the normal at $3 \mathrm{~d}$ (Table 2). The pulmonary arteries of the animals exposed to 3-14 d hypoxia and then allowed to recover did not show a significant reduction in muscle until after $6 \mathrm{~d}$ of recovery $(p=0.03)$ and muscle was still greater than normal (Table 2).

The bronchial smooth muscle area of all animals exposed for $0-3$ or 3-14 d hypoxia was still increased after 3 or $6 \mathrm{~d}$ recovery (Table 2). 
Table 2. Effect of hypoxia and recovery on bronchial and pulmonary arterial smooth muscle area

\begin{tabular}{lcc}
\hline & \multicolumn{2}{c}{$\begin{array}{c}\text { Smooth muscle area } \\
\left(\mu \mathrm{m}^{2} / \mu \mathrm{m}\right. \\
\text { luminal length })\end{array}$} \\
\cline { 2 - 3 } & \multicolumn{2}{c}{$\begin{array}{c}\text { Pulmonary artery } \\
\text { Bronchi }\end{array}$} \\
\hline 0-3 days hypoxia & $33 \pm 7 *$ & $11 \pm 0.7^{*}$ \\
3-d-old control & $39 \pm 6 \dagger \dagger$ & $6 \pm 0.4$ \\
0-3 hypoxia +3 d recovery & $22 \pm 2$ & $10 \pm 0.9 \dagger$ \\
6-d-old control & $68 \pm 9 *$ & $7 \pm 0.8$ \\
3-14 days hypoxia & $33 \pm 5$ & $18 \pm 1^{*}$ \\
14-d-old control & $51 \pm 8 \dagger$ & $9 \pm 0.9$ \\
3-14 hypoxia +3 d recovery & $32 \pm 6$ & $10 \pm 2 \dagger$ \\
17-d-old control & $43 \pm 8 \dagger \dagger$ & $20 \pm 2 \dagger$ \\
3-14 hypoxia +6 d recovery & $29 \pm 6$ & $12 \pm 1$ \\
20-d-old control & 0.6 \\
\hline
\end{tabular}

Following hypoxia, pulmonary arterial and bronchial smooth muscle area increased two-fold compared to age-matched controls. During recovery, pulmonary arterial but not bronchial smooth muscle decreased significantly compared to the pulmonary hypertensive animals.

$* p<0.001$ when hypoxic pulmonary hypertensive animals compared to age-matched controls; $\dagger p<0.01$ when recovery animals compared to age-matched controls; $\$ p<0.03$ when recovery animals compared to hypoxia-exposed animals.

Number of animals studied is shown in Table 1.

Values are mean + SEM

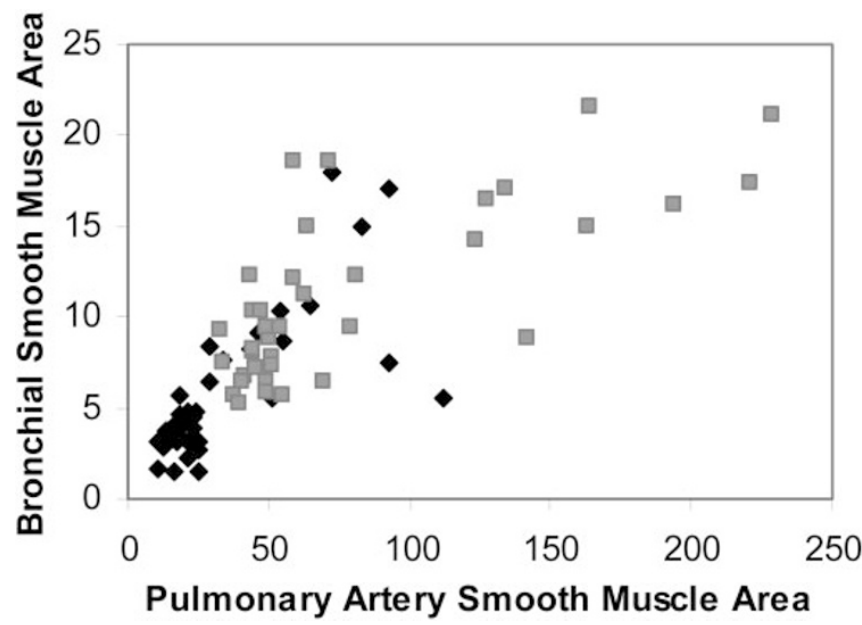

Figure 1. Relationship between bronchial and pulmonary arterial smooth muscle area. Scatter plot of smooth muscle area $\left(\mu \mathrm{m}^{2} / \mathrm{mm}\right.$ luminal length) of the paired pulmonary arterial and bronchial rings from the $3 \mathrm{~d}$ control (black diamond) and the 0-3 d hypoxic pulmonary hypertensive (grey squares) animals. There was a significant correlation between bronchial and pulmonary arterial smooth muscle area $\mathrm{r}=0.75, p<0.001$.

Organ chamber studies. In both the pulmonary arteries and bronchi, the dose-dependent contractile response to ET-1 was increased three-fold in the $0-3$ d hypoxic pulmonary hypertensive animals when compared with the $3 \mathrm{~d}$ control group, $p$ $<0.008$ (Fig. 2). Following $3 \mathrm{~d}$ of recovery, the pulmonary arterial ET-1-induced contractile responses had decreased and were not significantly different from those of the $6 \mathrm{~d}$ control group (Fig. 2). By contrast, in the bronchi the ET-1-induced contractile responses had not decreased and were significantly greater than in the $6 \mathrm{~d}$ controls, $p=0.01$ (Fig. 2).

Following a period of postnatal adaptation and 3-14 d hypoxia, pulmonary arterial contractile response to ET-1 was
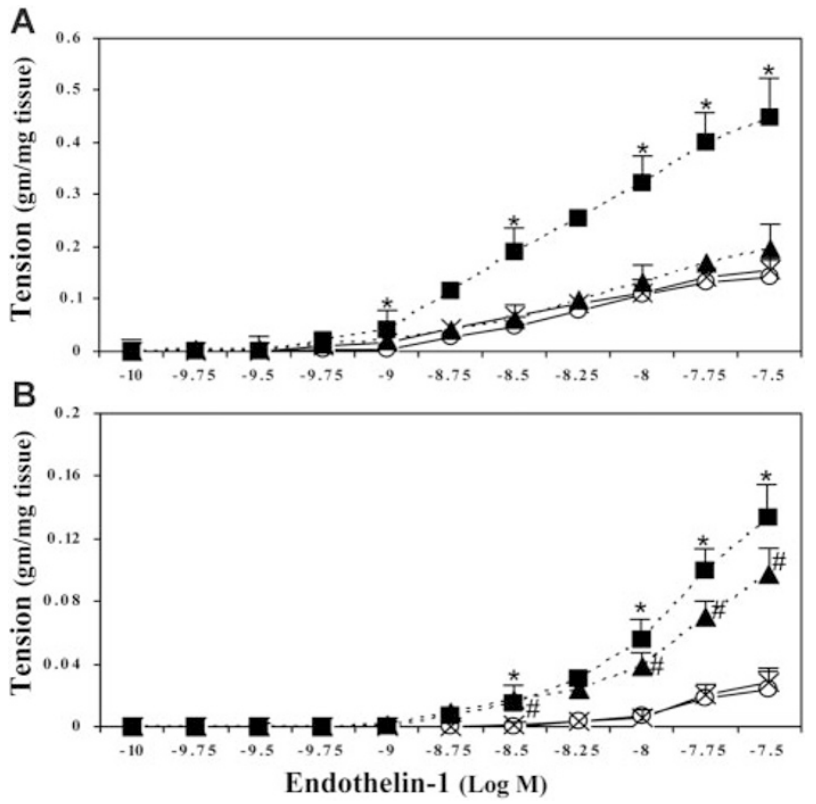

Figure 2. Contractile response curves for ET-1 after 3 d hypoxia and recovery. Contractile concentration-response curves for ET-1 in pulmonary arteries $(A)$ and bronchial rings $(B)$ in 0-3 d hypoxia (solid square), 3-d-old (cross), 0-3 hypoxia $+3 \mathrm{~d}$ recovery (solid triangle) and 6-d-old (open circle) pigs. The hypoxia-exposed tissue produced a greater contractile response compared with the 3 -d-old controls $(* p<0.05)$. Following $3 \mathrm{~d}$ recovery, the bronchial rings still had a significantly increased contractile response compared with the 6-d-old controls (\# $p<0.05$ ). Number of animals studied is shown in Table 1. Values are mean \pm SEM.

increased two-fold, and the bronchial contractile response was increased five-fold, $p<0.01$ (Fig. 3). Following $3 \mathrm{~d}$ of recovery, the pulmonary arterial response had decreased and was not significantly different from the age-matched control, however the bronchial responses remained significantly elevated, $p=0.04$ (Fig. 3). After $6 \mathrm{~d}$ of recovery, the pulmonary arterial and bronchial contractile responses were similar to those of the age-matched controls (Fig. 3).

The ET-1-induced relaxant responses seen in the pulmonary arteries of control animals were absent in all hypoxia-exposed animals (Table 3 ). Following $0-3 \mathrm{~d}$ hypoxia and $3 \mathrm{~d}$ recovery, the relaxant response was not significantly different from that seen in the 3 or $6 \mathrm{~d}$ control animals (Table 3). However following 3-14 d hypoxia and $3 \mathrm{~d}$ recovery, the pulmonary arterial relaxant response remained significantly impaired compared with controls, $p=0.01$ (Table 3). After $6 \mathrm{~d}$ of recovery, the relaxant response was similar to that of 20-d-old controls (Table 3 ).

The relaxant response when present was completely inhibited by the ET-B receptor antagonist BQ788, and the nitric oxide synthase inhibitor, L-NAME, suggesting that the relaxation was due to release of nitric oxide via the ET-B receptor (Table 3). No ET-1-induced relaxation responses were seen in the bronchi.

Hypoxic pulmonary hypertension reduced the maximal norepinephrine-induced relaxant response in the pulmonary arteries 10-fold and 3-fold from the 0-3 d and 3-14 d hypoxic pulmonary hypertensive animals, respectively $(p<0.001, p<$ 0.002; Figs. 4 and 5). 

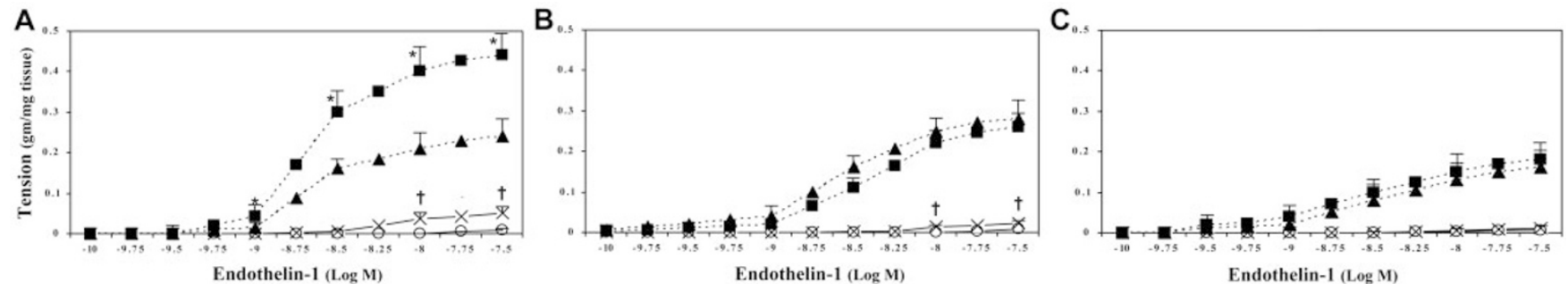

Figure 3. Contractile response curves for ET-1 after $11 \mathrm{~d}$ hypoxia and recovery. End of Hypoxic exposure $(A)$ : Contractile concentration-response curves for ET-1 in 3-14 d hypoxia pulmonary artery rings (solid square) and bronchial rings (cross) compared with 14-d-old control pulmonary arteries (solid triangle) and bronchi (open circle), showing that the hypoxia-exposed tissue produced a two-fold greater contractile response compared with the controls. Three-day recovery $(B)$ : Following 3-14 hypoxia $+3 \mathrm{~d}$ recovery, the bronchial rings (cross) but not pulmonary arterial rings (solid square) still had a significantly increased contractile response compared with the $17 \mathrm{~d}$ pulmonary arterial (solid triangle) and bronchial (open circle) controls. Six-day recovery (C): Following 3-14 hypoxia $+6 \mathrm{~d}$ recovery, both the bronchial (cross) and the pulmonary arterial (solid square) contractile responses were similar to the $20 \mathrm{~d}$ pulmonary arterial (solid triangle) and bronchial (open circle) controls. ${ }^{*} p=0.02$ when 3-14 d hypoxia pulmonary arteries compared with $14 \mathrm{~d}$ control; $\dagger p<0.04$ when hypoxia-exposed and recovery bronchi compared with age-matched controls. Values are mean \pm SEM.

Table 3. Relaxation of pulmonary arteries to ET-1 and in the presence of BQ788 or L-NAME

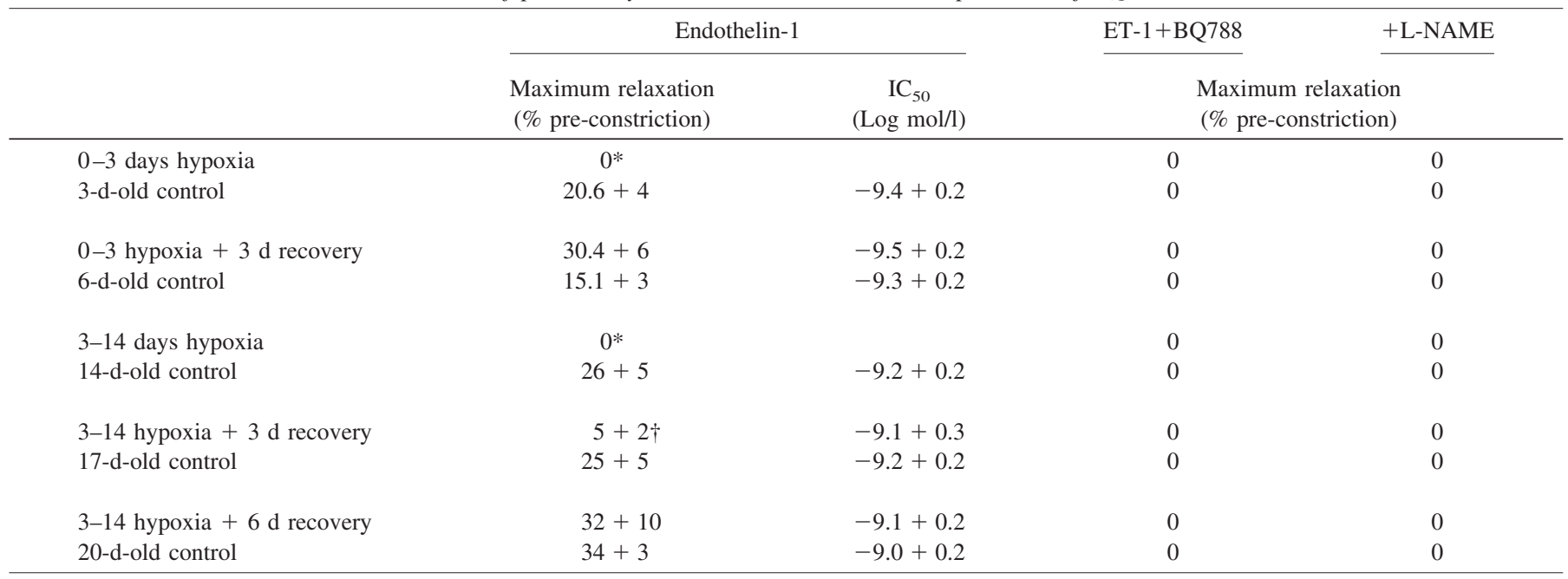

Pulmonary hypertension, BQ788 and L-NAME completely inhibited the ET-1-induced relaxation.L-NAME, ${ }^{\mathrm{w}}$-nitro-L-arginine methyl ester; IC ${ }_{50}$, the ET-1 concentration producing half-maximal concentration.

$* p<0.01$ when hypoxic pulmonary hypertensive animals compared to age-matched controls; $\dagger, p<0.01$ when recovery animals compared to age-matched controls.

Values are mean + SEM.
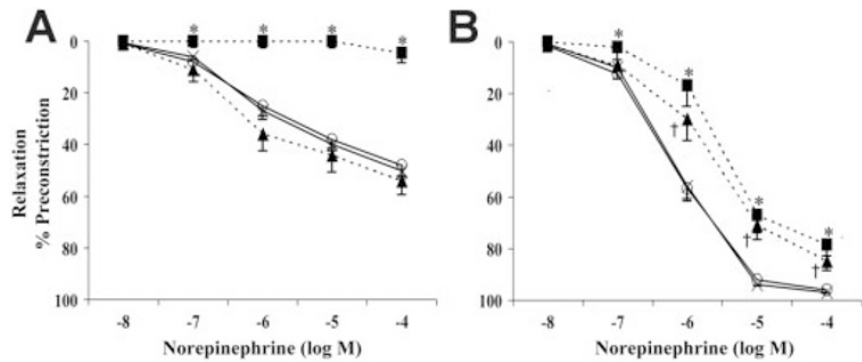

Figure 4. Relaxation response curves for norepinephrine after $3 \mathrm{~d}$ hypoxia and recovery. Relaxation concentration-response curves for norepinephrine in pulmonary arteries $(A)$ and bronchial rings $(B)$ from $0-3 \mathrm{~d}$ hypoxia (solid square), 3-d-old control (cross), $0-3$ hypoxia $+3 \mathrm{~d}$ recovery (solid triangle) and $6 \mathrm{~d}$ control (open circle) pigs. The hypoxia-exposed tissue produced an attenuated relaxation response compared with the $3 \mathrm{~d}$ controls $(* p<0.01)$. Following $3 \mathrm{~d}$ recovery, the bronchial rings still had a significantly impaired relaxation response compared with the $6 \mathrm{~d}$ controls $(\dagger p<0.01)$. Number of animals studied is shown in Table 1 . Values are mean \pm SEM.

In the normal bronchi, norepinephrine-induced relaxation is much greater than in normal pulmonary arteries. The response was significantly reduced by $20 \%$ in $0-3$ d hypoxia $(p=$
0.005 ) and $10 \%$ in $3-14 \mathrm{~d}$ hypoxia groups ( $p=0.01$; Figs. 4 and 5).

After 0-3 d hypoxia and $3 \mathrm{~d}$ recovery the pulmonary arterial norepinephrine-induced relaxant response was not significantly different from that in the 6-d-old control piglets (Fig. 4). By contrast, in the bronchi the norepinephrineinduced relaxation was still significantly impaired (Fig. 4). After 3-14 d hypoxia and $3 \mathrm{~d}$ recovery, both pulmonary arterial and bronchial norepinephrine relaxation responses remained significantly impaired compared with the control animals (Fig. 5). After $6 \mathrm{~d}$ recovery, the pulmonary arterial response was normal, but the bronchial response remained significantly impaired (Fig. 5).

\section{DISCUSSION}

We hypothesized that exposure to chronic hypoxia from birth and from $3 \mathrm{~d}$ would lead to a parallel increase in the amount of airway and pulmonary arterial smooth muscle, parallel changes in reactivity to contractile and relaxant ago- 

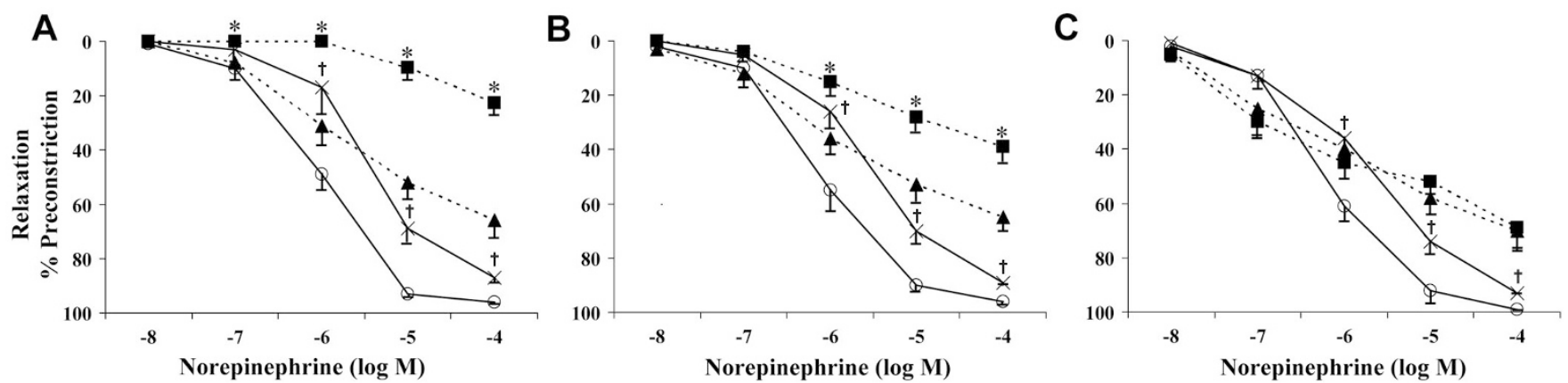

Figure 5. Relaxation response curves for norepinephrine after $11 \mathrm{~d}$ hypoxia and recovery. End of hypoxic exposure (A): At the end of 3-14 d hypoxic exposure, pulmonary artery rings (solid square) and bronchial rings (cross) produced a significantly attenuated relaxation response compared with the $14 \mathrm{~d}$ control pulmonary arteries (solid triangle) and bronchi (open circle). Three-day recovery (B): Following 3-14 hypoxia $+3 \mathrm{~d}$ recovery, the bronchial rings (cross) and pulmonary arterial rings (solid square) still had a significantly impaired relaxation response compared with the 17-d-old pulmonary arterial (solid triangle) and bronchial (open circle) controls. Six-day recovery $(C)$ : Following 3-14 hypoxia +6 d recovery, the pulmonary arterial (solid square) relaxation response was similar to the $20 \mathrm{~d}$ pulmonary arteries (solid triangle) but the bronchial (cross) relaxation response was still significantly impaired compared with the $20 \mathrm{~d}$ bronchial (open circle) controls. $* p<0.01$ when hypoxia-exposed and recovery pulmonary arteries compared with age-matched controls; $\dagger p<0.045$ when hypoxia-exposed and recovery bronchi compared with age-matched controls. Values are mean \pm SEM.

nists and that the pattern of structural and functional recovery when animals were returned to room air would be similar. We demonstrated that although there were parallel changes in the airway and pulmonary artery during pulmonary hypertension, during recovery the regression of bronchial structural and functional abnormalities was slower than those of the arteries.

Exposure to hypoxia from birth and from $3 \mathrm{~d}$ led to pulmonary hypertension as judged by right ventricular hypertrophy and an increase in pulmonary artery smooth muscle area, as previously described (11). We also demonstrated an increase in the amount of muscle in the adjacent airways. On recovery in room air for 3 and $6 \mathrm{~d}$, right ventricular and pulmonary arterial muscle regressed but was still excessive for age, as has previously been described $(9,10)$, while there had been no regression of the bronchial smooth muscle.

Human infants and children with pulmonary hypertension are known to have an increase in both bronchial and pulmonary arterial smooth muscle in congenital heart disease (1) and bronchopulmonary dysplasia (12). Anatomically, the pulmonary arteries and the bronchi lie in close proximity to each other and it is conceivable that a mediator or neurotransmitter released locally, such as ET-1, might act on both vascular and bronchial smooth muscle to produce co-hypertrophy and coconstriction of bronchial and vascular smooth muscle. In human embryos, the innermost pulmonary arterial smooth muscle cells appear to derive from the bronchial smooth muscle cells of the adjacent airways from 38-98 d gestation (13). This similar embryological origin may also predispose the pulmonary arteries and bronchi to respond in a similar manner in pulmonary hypertension.

For the pharmacology experiments, we studied paired arteries and airways from intra-parenchymal division 3-4 pulmonary vasculature. Although in the adult lung, much of the resistance is in the microvascular segment, in the young human and in young rabbits, pulmonary vascular resistance has been shown to reside mainly in the arteries and veins, with a shift to the microvascular segment occurring with increasing age (14). Structural and pharmacological changes in response to chronic hypoxia are similar in large muscular and resistance arteries $(10,15)$.

In the present study, the ET-1-induced pulmonary arterial and bronchial contraction both increased at least two-fold during hypoxic exposure, and ET-B receptor mediated relaxation was absent in the pulmonary arteries. Using the same experimental model, Noguchi (16) found that in piglets exposed to hypoxia from birth, the plasma ET-1 was greater than normal, the ET-1 receptor binding increased in both pulmonary arteries and bronchi, and ET-B binding density decreased. Similarly, in lung biopsies of patients with pulmonary hypertension due to congenital heart disease, Lutz (17) found a higher Endothelin-A receptor density in pulmonary arteries and lung parenchyma and low ET-B receptor expression. In a porcine model of endotoxic shock bosentan, a dual ET receptor antagonist, completely abolished both the pulmonary hypertensive response and the increased airway resistance indicating that both the pulmonary arterial and airway changes were mediated by ET-1 (18). Similarly in human pulmonary artery rings taken at lobectomy, the responsiveness to ET-1 was increased in patients with reversible airways constriction detected on preoperative pulmonary function testing (19), again supporting the concept of co-constriction of bronchial and adjacent pulmonary arterial smooth muscle.

We have previously shown that the pulmonary arterial relaxation response to norepinephrine in piglets greater than $24 \mathrm{~h}$ of age was largely mediated by nitric oxide release from the endothelium and that following exposure to hypoxia from birth for $3 \mathrm{~d}$, the relaxation response was absent or severely attenuated (20). We have now shown that norepinephrineinduced relaxation is also significantly decreased in the airways. Hislop (21) found that the normal postnatal increase in $\beta$ adrenoceptor density was attenuated in both pulmonary arterial endothelium and bronchial epithelium in piglets exposed to hypoxia from birth for $3 \mathrm{~d}$. Similarly lymphocyte $\beta$ adrenoceptor density was attenuated by $27 \%$ and platelet $\alpha$ adrenoceptor density was increased in children with congenital heart disease with left-to-right shunts and pulmonary 
hypertension (22). This reduction of $\beta$ adrenoceptors in pulmonary hypertension, in addition to impaired endothelial nitric oxide release (9), may explain the reduced adrenoceptor stimulated pulmonary arterial and bronchorelaxation we observed in our study.

Recovery in room air even for a comparatively short time led to changes in structure and function. In some instances recovery was rapid, as demonstrated by ET-1-induced nitric oxide release, while in others it was slower as in the reversal of right ventricular hypertrophy, and regression of bronchial structural and functional abnormalities. The implications of these findings are potentially clinically important, as some effects of pulmonary hypertension persist for long periods and may affect how patients react to subsequent illnesses and treatment. Schulz-Neick (23) found that persistence of a raised pulmonary vascular resistance following surgical repair of congenital heart defects resulted in significantly longer periods of postoperative mechanical ventilation.

In our study, pulmonary arterial smooth muscle had decreased after only 3 and $6 \mathrm{~d}$ recovery in normoxia, but bronchial smooth muscle mass was still similar to that seen at the end of hypoxic exposure. The lack of regression of bronchial smooth muscle was associated with persistence of the enhanced contractile response to ET-1 and the impaired relaxant response to norepinephrine. The clinical significance of these observations is uncertain but they may help explain the much higher prevalence of asthmatic symptoms and abnormal bronchial reactivity seen in six to 11-y-old survivors of neonatal meconium aspiration syndrome and pulmonary hypertension (24), although the respiratory management may also have influenced outcome in these patients (4). This suggests however that the bronchial abnormalities can persist for many years and further studies are required to examine the effects of longer periods of recovery.

In contrast to the bronchi, pulmonary arterial ET-1 mediated contraction recovered rapidly, having returned to levels similar to that in age-matched controls after $3 \mathrm{~d}$ of normoxic recovery in both pulmonary hypertension groups despite the muscle still being increased. In the same porcine model of neo-natal chronic hypoxia, the binding density of Endothelin-A receptors decreased and that of ET-B receptors increased to levels normal for age after $3 \mathrm{~d}$ recovery (16). Recovery of pulmonary arterial ET-1 and norepinephrine relaxation response was age-dependent. Recovery of relaxation response was rapid in the young piglets exposed to hypoxia from birth, being normal after $3 \mathrm{~d}$. However, in the older piglets exposed to hypoxia for 3-14 d after a period of postnatal adaptation, the relaxation response was still impaired after $3 \mathrm{~d}$, but was normal after $6 \mathrm{~d}$ of recovery. This may be due to either the age of the piglets or the longer duration of exposure to hypoxia.

In summary, we present evidence of co-hypertrophy and co-constriction of bronchial and vascular smooth muscle in an experimental model of neo-natal pulmonary hypertension. Arterial contractile and relaxant responses recovered rapidly, with a slower recovery of the arterial wall structure and right ventricular hypertrophy. The amount of bronchial smooth muscle and its responsiveness recovered the least. These findings support and may help explain clinical reports of persistent compromise of pulmonary vascular and airway function in those who survive neo-natal pulmonary hypertension. Longer follow-up experimental studies are indicated.

\section{REFERENCES}

1. Schindler MB, Bohn DJ, Bryan AC, Cutz E, Rabinovitch M 1995 Increased respiratory system resistance and bronchial smooth muscle hypertrophy in children with acute postoperative pulmonary hypertension. Am J Respir Crit Care Med 152:1347-1352

2. Garg M, Kurzner SI, Bautista DB, Lew CD, Ramos AD, Platzker AC, Keens TG 1992 Pulmonary sequelae at six months following extracorporeal membrane oxygenation. Chest 101:1086-1090

3. UK Collaborative ECMO Group 1998 The collaborative UK ECMO (Extracorporeal Membrane Oxygenation) trial: follow-up to 1 year of age. Pediatrics 101:E1

4. Dreyfuss D, Saumon G 1998 Ventilator-induced lung injury: Lessons from experimental studies. Am J Respir Crit Care Med 157:294-323

5. Sartori C, Allemann Y, Trueb L, Delabays A, Nicod P, Scherrer U 1999 Augmented vasoreactivity in adult life associated with perinatal vascular insult. Lancet 353:2205-2207

6. Rosenberg AA, Kennaugh J, Koppenhafer SL, Loomis M, Chatfield BA, Abman SH 1993 Elevated immunoreactive endothelin-1 levels in newborn infants with persistent pulmonary hypertension. J Pediatr 123:109-114

7. Ishikawa S, Miyauchi T, Sakai S, Ushinohama H, Sagawa K, Fusazaki N, Kado H, Sunagawa H, Honda S, Ueno H 1995 Elevated levels of plasma endothelin-1 in young patients with pulmonary hypertension caused by congenital heart disease are decreased after successful surgical repair. J Thorac Cardiovasc Surg 110:271-273

8. Knirsch W, Eiselt M, Nurnberg J, Haas NA, Berger F, Dahnert I, Uhlemann F, Lange PE 2002 Pulmonary plasma catecholamine levels and pulmonary hypertension in congenital heart disease. Z Kardiol 91:1035-1043

9. Tulloh RM, Hislop AA, Haworth SG 1999 Role of NO in recovery from neo-natal hypoxic pulmonary hypertension. Thorax 54:796-804

10. Hall SM, Hislop AA, Wu Z, Haworth SG 2004 Remodelling of the pulmonary arteries during recovery from pulmonary hypertension induced by neo-natal hypoxia. J Pathol 203:575-583

11. Haworth SG, Hislop AA 1982 Effect of hypoxia on adaptation of the pulmonary circulation to extra-uterine life in the pig. Cardiovasc Res 16:293-303

12. Bush A, Busst CM, Knight WB, Hislop AA, Haworth SG, Shinebourne EA 1990 Changes in pulmonary circulation in severe bronchopulmonary dysplasia. Arch Dis Child 65:739-745

13. Hall SM, Hislop AA, Pierce CM, Haworth SG 2000 Perinatal origins of human intrapulmonary arteries-formation and smooth muscle maturation. Am J Respir Cell Mol Biol 23:194-203

14. Raj JU, Chen P, Navazo L 1986 Micropuncture measurements of lung microvascular pressure profile in 3- to 4- week - old rabbits. Pediatr Res 20:1107-1111

15. Boels PJ, Deutsch J, Gao B, Haworth SG 1999 Maturation of the response to bradykinin in resistance and conduit pulmonary arteries. Cardiovasc Res 44:416-428

16. Noguchi Y, Hislop AA, Haworth SG 1997 Influence of hypoxia on endothelin-1 binding sites in neo-natal porcine pulmonary vasculature. Am J Physiol 272:H669_ H678

17. Lutz J, Gorenflo M, Habighorst M, Vogel M, Lange PE, Hocher B 1999 Endothelin-1 and endothelin receptors in lung biopsies of patients with pulmonary hypertension due to congenital heart disease. Clin Chem Lab Med 37:423-428

18. Albertini M, Ciminaghi B, Mazzola S, Clement MG 2001 Improvement of respiratory function by bosentan during endotoxic shock in the pig. Prostaglandins Leukot Essent Fatty Acids 65:103-108

19. Cases E, Vila JM, Medina P, Aldasoro M, Segarra G, Lluch S 1996 Increased responsiveness of human pulmonary arteries in patients with positive bronchodilator response. Br J Pharmacol 119:1337-1340

20. Schindler MB, Hislop AA, Haworth SG 2004 Postnatal changes in the response to norepinephrine in the normal and pulmonary hypertensive lung. Am J Respir Crit Care Med 170:641-646

21. Hislop AA, Mak JC, Kelly D, Reader JA, Barnes PJ, Haworth SG 2002 Postnatal changes in beta-adrenoceptors in the lung and the effect of hypoxia induced pulmonary hypertension of the newborn. Br J Pharmacol 135:1415-1424

22. Dzimiri N, Galal O, Moorji A, Bakr S, Abbag F, Fadley F, Almotrefi AA 1995 Regulation of sympathetic activity in children with various congenital heart diseases. Pediatr Res 38:55-60

23. Schulz-Neick I, Li J, Penny DJ, Redington AN 2001 Pulmonary vascular resistance after cardiopulmonary bypass in infants: effect on postoperative recovery. J Thorac Cardiovasc Surg 121:1033-1039

24. Macfarlane PI, Heaf DP 1988 Pulmonary function in children after neo-natal meconium aspiration syndrome. Arch Dis Child 63:368-372 